\title{
Public Private Partnerships and Collaboration in the Health Sector in the Kingdom of Saudi Arabia: A Qualitative Study
}

\author{
Amal Almalki ${ }^{1} \&$ Mohammed Khaled Al-Hanawi ${ }^{2}$ \\ ${ }^{1}$ Radiology and Medical Imaging Department, King Fahad Armed Forces Hospital, Jeddah, Saudi Arabia \\ ${ }^{2}$ Health Services and Hospitals Administration Department, Faculty of Economics and Administration, King \\ Abdulaziz University, Jeddah, Saudi Arabia \\ Correspondence: Mohammed Khaled Al-Hanawi, Health Services and Hospitals Administration Department, \\ King Abdulaziz University, Jeddah, 21589, P O Box 80200, Saudi Arabia. Tel: 966-556-522-222. E-mail: \\ mkalhanawi@kau.edu.sa
}

Received: March 18, 2018 Accepted: April 9, 2018 Online Published: April 23, 2018

doi:10.5539/gjhs.v10n6p10 URL: https://doi.org/10.5539/gjhs.v10n6p10

\begin{abstract}
A public-private partnership (PPP) is defined as a collaboration between the public and private sectors in the financing, delivery and development of public goods and services. This phenomenon has been adopted globally by many as a new economic paradigm. This study identifies challenges and other hindrances in promoting PPPs, identifies the concrete contribution of PPP initiatives in improving healthcare service delivery and determines the level of participation of the private sector in healthcare delivery systems under PPP initiatives in the Kingdom of Saudi Arabia. Semi-structured interviews were conducted with 13 participants, including 4 government hospital directors, 5 private hospital directors and 4 health personnel. Participants were interviewed face to face, and the interviews were audio-recorded. The participants were purposefully selected based on their knowledge and familiarity with the implementation of PPP schemes. The evidence showed that the most important benefits of adopting a PPP are the quality of service, the speed at which low-cost healthcare service delivery is made accessible and the diversification of risks between the two sectors so that neither the private sector nor the public sector bears the entire risk alone. The results also revealed that PPPs will lead to increased efficiency and accuracy with respect to the design and implementation of infrastructural projects as well as the financing, execution, maintenance and development of the healthcare sector - the implementation of which makes high-quality services available to end users. Risk sharing is of great importance for the healthcare sector in that it helps hospitals to avoid closure and failure, distributes financial flows in an ideal way, and reduces the pressure on hospitals to work in a safe investment environment. This aim can be achieved through increasing the partnerships between public and private sectors.
\end{abstract}

Keywords: public-private partnership, cost sharing, resource sharing, risk sharing, public sector, private sector, healthcare services delivery, Saudi Arabia

\section{Introduction}

The issue of public-private partnership (PPP) received great attention from governments, communities and research centres around the world after it became apparent that the process of economic and social development depends on gathering the full potential of a society, including the capabilities, resources and expertise of both the public and private sectors. PPPs help institutional organizations establish and operate projects of different types and scale after each independent institutional organization has faced challenges and difficulties in achieving their development goals at the target level.

The healthcare sector in the Kingdom of Saudi Arabia (KSA) is one of the top priorities of the Saudi government. The government has wholly nurtured the healthcare sector into one of the largest and most prominent on the globe over the past decade (Almalki, FitzGerald, \& Clark, 2013). Although the healthcare sector has shown a large and expanding market and the government has allocated an increasing percentage of the national budget to the sector year by year, the participation of the private sector is pegged at only $32 \%$ in the KSA (Ministry of Health [MOH], 2015). Within the Gulf Cooperation Council (GCC) region, the KSA leads in terms of the financing and expenditures of healthcare services and commits close to $3.6 \%$ of the annual gross domestic product (GDP) to healthcare financing (Alkhamis, Hassan, \& Cosgrove, 2014). 
The healthcare services in the KSA are provided through three main sectors: the MOH, other government sectors and the private sector. The public sector, including the $\mathrm{MOH}$ and other government sectors, provides the bulk of services (Al-Hanawi, Alsharqi, Almazrou, \& Vaidya, 2018). The private sector delivers healthcare services through private hospitals, clinics, laboratories, pharmacies and physiotherapy centres, offering a total of 152 private hospitals with 17,428 hospital beds (MOH, 2015). Private hospitals represent only $32 \%$ of the total number of hospitals in the country. It is worth noting that most of the private healthcare services are provided in the major cities in the country. The highest percentage ( $25 \%, 38$ hospitals) of private hospitals is present in the Jeddah region. This is followed by the Riyadh region, where $24.3 \%$ of private hospitals are present ( 37 hospitals). In the Riyadh region, there are 5004 private hospital beds, constituting the highest percentage (28.7\% of the total). This is followed by the Jeddah region, which has $20.2 \%$ of the hospital beds in the private sector (MOH, 2015).

Population growth will indeed place a drastically increased demand on healthcare services in the KSA. While the Saudi Ministry of Health has rolled out an integrated and comprehensive 10-year strategic plan (2010-2020) for the healthcare system in response to its mandate to provide healthcare services to all its citizens, it has also identified funding as one of its major challenges (MOH, 2010). Consequently, the healthcare service in the KSA is seen as a promising area for collaboration that requires a robust PPP initiative.

How does a PPP come into practice? The push for public-private partnerships for healthcare services should be distinguished from the trend of privatization, which is the private sector for-profit provision of healthcare services. In the case of privatization, the public health policy goal and the rules under which for-profit entities operate are set and enforced solely by government agencies (Widdus, 2001). However, PPPs have been adapted to a large extent as a tool for "cooperation and durability of some sort of between public and private actors in which they jointly develop products and services and share risks, costs, and resources which relate to these products" (Van Ham \& Koppenjan, 2001, p.598). PPPs are widespread and are considered an effective way to achieve a better value for money in delivering projects (Ke, Wang, Chan, \& Lam, 2010; Alsharqi \& Al-Hanawi, 2017). PPPs are also built on the expertise of each partner, which helps to meet public needs through the appropriate allocation of costs, resources and risks (Chakravarty, Sadhu, Bhattacharjee, \& Nallala 2015). Hence, PPP benefits can be seen in sharing risks, costs and resources.

As a result of the foregoing discussion, this study aimed to investigate the current situation of PPP initiatives in the KSA healthcare system. It also aimed to determine how the access of all citizens to healthcare services as a constitutional right benefited from this mode of partnership.

\section{Literature Review}

\subsection{Contextual Framework of Public-Private Partnerships}

Countries all over the globe agree that it is the main mandate of every state or government to ensure the general welfare of its citizens. In adherence to this mandate, governments must efficiently deliver public goods and services to its people. However, the efficiency of production and delivery requires multi-stakeholder participation, which is within the disposal of the public and private sectors. As populations grow in every country, governments are usually burdened with mobilizing an increasing number of resources to finance the production and delivery of public goods and services.

The concept of PPP is not new. However, recently, PPPs have received special attention and support from economic and political agents, including policy makers at national, regional and local levels (Linder \& Vaillancourt Rosenau, 2000). Thus, globally, PPPs have been widely used as a tool for cooperation. This concept was developed by a group of public and private sector representatives working together on an energy project in the United States. The idea was to run that project like a private business but still be publicly accountable (Mistarihi \& Khasawneh, 2015). This rapid and widespread acceptance of PPPs is supported by the notion that partnerships are a cost-efficient and effective means for executing public policy across a variety of policy agendas.

PPP is a concept that has become widely used despite the absence of a clear definition (Organisation for Economic Co-operation and Development [OECD], 2012). Generally, the term refers to a contractual agreement between public and private sector entities, which together enhance the delivery and operation of public infrastructure projects, such as roads, prisons and hospitals (Wong, Yeoh, Chau, Yam, Cheung, \& Fung, 2015). It is notable that the concept shifts the role of public sector clients from being owners or operators of infrastructure projects into that of being purchasers of long-term services from the private sector, which is often responsible for designing, building, financing and operating the asset. According to Pollock \& Price (2006), PPPs are time- and cost-specific agreements between the state and a private consortium for infrastructure-based service provision. The consortium usually undertakes responsibilities for financing, designing, and constructing (or refurbishing) a facility and/or 
thereafter providing services. The government (or service user) provides the consortium with a revenue stream that is used to repay debts, fund operations and provide a return to investors.

When the market fails to distribute health benefits to people who need them, especially to poor people in developing countries, partnerships between public and private organizations are often seen as offering an innovative method with a good chance of producing the desired outcomes (Reich, 2002). No matter how much the application of PPPs varies in different countries, PPP has evolved into an institutionalized form of cooperation of public and private actors, which, on the basis of their own indigenous objectives, work together towards a joint target (Jamali, 2004).

\subsection{Challenges in Implementation}

In recent years, the trend in both developed and developing countries has been towards greater private sector involvement in healthcare provision and financing. Reasons for this trend include insufficient government resources and poor performance on the part of the public sector (Lim, 2005). In this context, various countries engage public-private partnership as a proactive measure to resolve the fiscal deficit on their side. However, the OECD observed from various consultations conducted and from actual experiences that many misunderstandings about PPP pose considerable challenges to its implementation. According to the OECD (2012), the common misunderstandings are as follows:

- $\quad$ PPPs as a substitute for public investment/resources - Governments sometimes identify PPPs as an alternative to public procurement due to a lack of public sector funds or fiscal capacity. This demonstrates a lack of understanding of PPP transactions. The state is purchasing an asset or providing a service, which will incur costs for the state. PPPs do not provide a "free" infrastructure, as the nature of the private sector means that it cannot construct and operate facilities without being adequately compensated for the costs and risks involved.

- $\quad$ PPP as a revenue generator for the government or its agencies - Governments and their agencies and departments sometimes opt for a PPP project in hopes of generating net revenue for the state. It is difficult to see how this could be the case under either an availability-based scenario or a user-payment concession scenario. It is obvious that an availability-based PPP will not generate net revenue for the state but will, on the contrary, entail a commitment of expenditures over a number of years. Under a concession user-pay PPP, any revenue that is collected by the concessionaire is revenue that could have been collected by the state if the project was conducted by public procurement minus the increased debt-service costs and return on equity associated with private-sector participation. Under this analysis, concession-based PPPs that are viewed as revenue positive by governments are actually revenue negative.

- PPPs remove all risk for the state. In the course of ISMED Program work, government officials have sometimes stated that they wish to pursue PPPs so that the state can avoid all risk by transferring the risk entirely to the private sector. When combined with the notions discussed above that a concession arrangement is cost free and will provide net revenue, PPPs can be seen as very attractive. However, just as the idea that PPPs are cost free is false, so is the idea that all risk can be transferred.

On the other hand, Kinlaw (2008) noticed the following challenges:

- Funding Risk - Risk that public health insurance funding will decline and become unsustainable for the operator.

- Payment Risk - Risk that payments will be delayed and cause liquidity issues within the public facilities.

- Political Risk - Risk that a new local political environment may not value working with the private sector.

It was also recognized that the implementation of PPP construction developments identified eight highly significant challenges, namely, deficiency of suitable legislation, prolonged concession agreements, deficiency in toll- or user fee-setting guidelines, too-high rates of return to private investors, lack of revenue-sharing formulae, inconstant implementation of evaluation tools, poor terms for the condition of assets at the end of the concession and poor risk allocation between the public and private sectors (Ngoma, Mundia, \& Kaliba, 2014). Subsequently, project approval by stakeholders, corruption, inflation, environmental consideration and lack of experience in PPP arrangements were the most significant risks of implementing PPP construction projects. This issue is especially relatable to the KSA government, as it has only recently decided to venture into the idea of PPP.

To closely assess and identify concrete benefits to the delivery of healthcare products and services, the actual 
experiences of managers and healthcare personnel engaged in operating healthcare PPPs can be deemed as evidence for how beneficial PPPs can be. Ricks, van Rooyen, Gantsho, and ten Ham (2013) conducted such a study, where an actual healthcare PPP was implemented in a semi-rural district in Eastern Cape Province, South Africa. Managers and healthcare personnel were interviewed, and their experiences from their involvement with the PPP in the operational stage were cited. In this study, it was found that PPPs enhanced healthcare delivery measures and provided conjoint advantages for both collaborators. Effective mediators were identified as good communication and rapport, assistance from authorities, and determination and solid liability from both partners. PPPs were hence proven to have what it takes to facilitate public healthcare services with effectiveness and competence.

In this light, several countries engaging in PPPs are faced with the challenging notion that legal and political concerns impose constraints on partnerships with the private sector. This collaboration with the private sector can often be misinterpreted as a subtle transition to privatization. These negative apprehensions have probably resulted from the private sector's social aura as manipulative and profit motivated. Thus, it is presumable that a bureaucracy may be cooperative with the private sector for organizational efficacy, while the political and well-known opinions can impede a smooth partnership deal.

Molchanova (2016) also described the challenges of PPP project implementation in healthcare in Russia and identified the lack of concrete validation of public-private partnership implementation in healthcare and the lack of standard models for instituting associations between PPP participants as being the most noteworthy constraints of PPP execution in the Russian healthcare sector.

Similarly, Pakistan has ventured into the public-private partnership scheme as well, presuming that it will help in the country's progress. Unluckily, the relationship of its government and the private sector has yet to become ideal. As such, the efforts for improved cooperation between the two sectors have been insufficient, albeit lacking. Thus, Tahir (2017) has emphasized that to overcome these hindrances and constraints in the implementation of public-private partnership for the improvement of the healthcare system, the government must initiate teamwork. The government has the utmost authority, accountability and monetary guarantee and thus has the means to pilot all the stakeholders, thus strengthening the partnership.

\subsection{Concrete Benefits of Public-Private Partnership in Healthcare Service Delivery}

The Ngoma et al. (2014) study assessed the benefits of PPPs on the infrastructure development in Zambia; self-administered questionnaires were used to consider the experiences of the participants in the PPP construction projects. Their findings identified five advantages categorized by the respondents from the public and private sectors: a decrease in the risk of handling, enhanced levels of amenities, economic advantages, savings in terms of structure-related expenses and enhanced infrastructure provision. PPPs hence apparently provide opportunities that encourage ventures in infrastructure improvement and, subsequently, economic progression. In this study, it was pre-supposed that the implementation of such partnerships could help improve the setback of inadequate health service delivery at two points: first, to enhance delivery approaches, and second, to improve the mobilization of supplies intended for health care. Additional advantages include advancement in the quality of amenities, reduction in the cost of care, redirection of public resources to other fields, decline in the doubling of services, implementation of paramount performance, more efficient and directed services to underprivileged citizens and improved self-regulation and liability.

The Higher Education Funding Council for England (1998) has highlighted three main public client objectives relating to PPPs. These objectives include i) better value for money by achieving improved services at lower costs than can be obtained by traditional public procurement routes; ii) the use of private sector funds, technologies, managerial skills and operational efficiency; and iii) the transfer of design, construction and operational risks as well as revenue stream risks and technological deterioration risks to the private sector. It is undisputed that the most usual motive for the implementation of a partnership is the economic advantages. These advantages are often realized through sharing risks, costs and resources.

\subsubsection{Risk Sharing}

Raman \& Björkman (2009) also expounded on the design of PPPs. In their study, it was also reported that the risk vulnerability of the partners is another critical issue in public-private partnerships. Perception of this risk is dependent on two factors: the rule-bound attitude of the partners with stern deterrents for deviance and the concept of trust among the partners. The risks diverge at varying levels of health representatives and are grounded on the extent of the services. At the level of policy, the stakes are relatively politically inclined. Popular opinions, such as those fostered by the media, political parties, health action groups, and staff unions, can prevent the government from taking explicit action against the private sector, particularly the sector that focuses on gaining profit. This 
hindrance is apparent in the notion that the private sector's chief interest is to earn profits. Subsequently, the private sector appears to be an exploiter.

The risks for the public and the private partners involve several aspects at the operational stage. The private sector faces financial risks, performance and accountability risks, risk of disagreement among stakeholders and reputational risks (Raman \& Björkman, 2009). Despite having the private sector's capability of enduring financial risks in the execution of the strategy, any mistake by a public partner can disintegrate the organization. This is a great tendency, especially in the accounting systems of governmental organizations, which are relatively outdated; hence, slip-ups cause unanticipated problems and complications. The public sector's budget shortage can lead to the termination of services to the beneficiaries, making the complications worse. Partnering with the private sector can help amend these kinds of risks and complications.

Another risk that can be shared and subsequently transferred to private partners is the risk of achieving superior facility standards. In addition, risks of building or infrastructure postponements, matters related to human resource departments, and inefficiencies in general are handed over to the private partners. Nevertheless, the public sector is not totally free from these risks, for it is still accountable for addressing communication with the society and for assuring that the monetary obligations to the for-profit partners are fulfilled.

\subsubsection{Cost Sharing}

In sharing costs between public and private partners, the total expenditures for professional services, including the expenses for assessments and contract administration activities, could be significantly abridged. In addition, the risks of project overruns may be lessened by design-build agreements. The for-profit partners have the capability to lower the budget for the management or maintenance of services by the application of economies of scale, advanced machineries, purchasing and reimbursement agreements that are more accommodating (Ngoma et al., 2014).

\subsubsection{Resource Sharing}

In Acharya and colleagues' study (2017) regarding the implementation of PPPs for mental healthcare service delivery in low-resource settings in rural Nepal, it was established that partnering with the for-profit sector provides an opportunity to co-invest in such partnerships, hence alleviating the scarcity in resources. However, their study also identified that the principal challenge in executing such a strategy is the reluctance of the public sector to collaborate with small private sector organizations. This is probably due to the observations that the for-profit organizations often function with preferably insignificant liability and appear to be more of a rival than a partner with the public sector.

\subsection{Elements of Success}

Greater benefits from PPP initiatives may be achieved depending on the level of success that has been gained. The OECD (2012), in its report on various models of PPP arrangements in the Middle East and North Africa, has identified the following requirements for successful implementation:

1. Rule of law/dispute resolution - PPPs are, at their most basic level, a contractual arrangement between a public authority or state-owned entity and a private party. As such, they are built upon contract law. Therefore, the rule of law and the protection of property rights and contractual rights are a key requirement if a PPP is to be successful. Clear, predictable and transparent rules for dispute resolution should be in place to resolve disagreements between the public and private parties.

2. Capacities of governments - PPPs are complex contractual and financial arrangements, and it is unlikely that government participants will have the necessary skills and knowledge to structure the transaction and manage the contract over its lifespan.

3. High-level political commitment - procurement by a PPP as opposed to traditional procurement is fundamentally a political decision made at the highest levels of government. Procurement by a PPP will often be entirely new to the officials implementing the decision, and the process will often be difficult. It is essential not only that those at the political level be committed to PPP procurement but also that they are seen by others to be committed.

4. Institutional structures and a legal/regulatory framework - the policy framework is critical for public-private partnerships even if much of the analysis tends to focus on the economics, risks and financial implications of PPPs. Pre-existing procurement and investment legislation and sector-specific legislation are often inadequate for public-private partnerships. At all stages of the PPP process, there must be a clear and transparent legal framework that both the public and private parties trust.

While several studies globally related to PPP in healthcare have already been conducted, most of them examine the 
dynamics, challenges and successes of this institutional arrangement, also highlighting its fundamental partnership principles. While these concepts were not the main focus of the present investigation, they significantly provided its context. As a significant contribution to the continuing research on PPP, this particular study aimed to investigate the current situation of PPP initiatives in KSA healthcare. It also aimed to determine how the access of all citizens to healthcare services as a constitutional right benefits from this mode of partnership.

\section{Materials and Methods}

This research employed qualitative semi-structure interviews. Qualitative research is an approach used for describing, explaining, and interpreting collected data and can also be described as an effective model that occurs in a natural setting, enabling the researcher to develop a level of detail from being highly involved in the actual experiences. A qualitative approach is exploratory and seeks to explain 'how' and 'why' a particular phenomenon or programme operates as it does in a particular context. As such, qualitative research often investigates local knowledge; the understanding of a given issue or programme; the experiences, meanings and relationships of various individuals; and the social processes and contextual factors (e.g., social norms and cultural practices) that marginalize a group of people or impact a programme (Creswell, 2017). Qualitative research often focuses on a limited number of respondents who have been purposefully and strategically selected to participate because of their knowledge of an issue or topic to be discussed.

In this study, an informative analysis of PPP in healthcare delivery was employed, including in-depth examinations of past literature, evaluation of reports from different health facilities in different states and countries implementing PPPs, and key informant interviews. The sampling population of the study was selected purposefully based on the participants' knowledge, experience and familiarity with the implementation of PPP schemes. In this technique, the researcher handpicked the participants based on their knowledge or association with the implementation of PPP in healthcare delivery systems. The variation of behaviours or answers of the respondents were increased by allowing the respondents to recommend other potential respondents that could be included or be of help in the study.

The sample size of this study consisted of 13 experienced participants from both the public and private sectors. The interviews were conducted in the Arabic language and were held over three months from September 2017 to December 2017. The interviews were conducted face-to-face by the main researcher (AA) and were audio-recorded.

It is argued that one of the main advantages of in-depth interviews is that the interviewer can dive into a direct dialogue with the respondent; as a result, more time can be saved in data collection. Moreover, the researcher can discuss the topic with the respondent freely and without boundaries. In addition, the interviewer can observe the reaction of the respondent immediately, and consequently, the observations can be written down by the researcher. This advantage may not be obtainable using other means of data collection (Cooper \& Schindler, 2003).

Face-to-face interviews are the most appropriate way to discuss a subject that is very sensitive, but not personal, and if the questions to be asked are very complex and thus inconvenient to discuss via an in-group format (Mathers, Fox, \& Hunn, 2007). The semi-structured interview guide (Appendix A) was developed on the basis of a comprehensive review of the relevant literature and previous studies on PPPs. For the purposes of the study and to ensure that the main topics were covered systematically, the interviews were structured into six main sections.

The first section of the interview collected general information about each participant. The second section was designed to discover the participant's knowledge about PPPs. The third section was designed to determine the participant's opinion about the benefits of applying PPPs in Saudi Arabia. This section included questions on the advantages and benefits of PPPs and the participant's opinion regarding cost sharing, risk sharing, and resource sharing and which one is most beneficial in PPPs. The fourth section investigated the challenges and policy gap in the implementation and the participant's opinion regarding actions to avoid the challenges in the future. The fifth section investigated the participant's opinion on the roles of the private sector. It included questions regarding their opinion on the role of the private sector in primary healthcare, pharmaceuticals and medical supplies, diagnostic services and human resource development. The final section included questions about successful PPPs in the country and any additional information the participants wanted to share, as shown in Appendix (A).

An interview session was conducted with a prior scheduled appointment at the most convenient venue chosen by the participant. The interviews were recorded and then transcribed by the interviewer after the session. The ethical issues of the study were considered. The interview duration varied between participants. It lasted between 30 and 45 minutes and was audio-recorded after informed consent was obtained. Participants were informed that they were free to withdraw at any time without giving a reason and that all information and opinions provided would be 
anonymous and confidential.

Qualitative data analysis seeks to pay attention to the 'spoken word', context, consistency and contradictions of views, and the frequency, intensity and specificity of comments, as well as emerging themes and trends. A framework analysis method was used to analyse the data. A framework analysis is a process where the researcher seeks to reduce and make sense of vast amounts of information, collect descriptive information and offer an explanation or interpretation. The analysis consists of seven steps: transcription, familiarization with the interview, coding, developing a working analytical framework, applying the analytical framework, charting data into a framework matrix and interpreting the data (Gale, Heath, Cameron, Rashid, \& Redwood, 2013).

\section{Results}

This section presents the results of the framework method analysis used to analyse the qualitative data. The researcher explored the opinions of 13 participants, including 4 government hospital directors, 5 private hospital directors, and 4 health personnel. The opinions of the respondents and their answers to key questions were compared to highlight the similarities and differences.

\subsection{Opinions and Benefits of Applying PPP}

Opinions of most of the sample focused on a positive view of PPPs, where participants saw that applying this partnership would provide high-quality services, raise the level of health care across the region and reduce the cost of healthcare compared to its cost in the private healthcare sector. According to these opinions, managers of private hospitals did not show excitement for this partnership compared to managers of public hospitals.

\subsubsection{Cost Sharing}

Most of the participants from all sectors believed that implementing a strong public-private partnership will reduce spending and contain costs, especially those related to the burden of chronic patients, but the participants were concerned about the outcomes of this partnership because they did not have enough knowledge and experience in this partnership. Two participants from the public sector agreed that experience in the private sector might help to meet healthcare requirements characterized by reliability and lower costs to the public sector. Three participants from the public sector disagreed with them and instead believed that cost sharing would reduce the quality of healthcare services provided to patients and would negatively affect the competitive advantage of private hospitals in the kingdom. Six participants believed that the partnership between both public and private sector enables the reduction of costs imposed on patients and that the mechanism of this partnership is the most important way of organizing this relationship to contain cost.

Most participants agreed that healthcare costs are high for the state and put pressure on the budget; however, the PPP would provide a new way to cover the costs of the expected increase in the healthcare demands and expand the abilities of their healthcare system. One participant stated that the PPP strategy enables the reduction of costs by ensuring quality treatments and ensuring that all other costs are kept to a minimum. This strategy can also indirectly reduce costs to patients by bringing services closer to their places of residence and workplace.

\subsubsection{Resource Sharing}

In general, all participants agreed that implementing PPP would give both sectors the advantages of resources that could be useful for patients. Three participants from the public sector agreed that PPP would yield better results than each sector alone could achieve. This would occur through the influence of the partners on each other's goals and values by negotiating and reaching better working standards. On other hand, there would be an expansion of financial resources because of the cooperation of the parties and the ability of the private sector to provide the necessary financing for the services. Two participants agreed that implementing PPP would create a common responsibility of both sectors for providing, operating and funding healthcare services.

\subsubsection{Risk Sharing}

Three participants stated that PPP is a long-term partnership aimed at providing public services and building infrastructure by using the administrative efficiency and financing capabilities of the private sector. Furthermore, this partnership is not only a partnership of capital and profit but also a partnership of risks, so that the public sector allocates a portion of the risks to the private sector and retains the others.

Two participants from the private sector agreed that implementing PPP would maintain private hospitals, some of which face risks that may affect their sustainability. Another two participants from the private sector thought that the private sector in this partnership contract is responsible for the risks of development, design, construction, operating, financing and inflation. The importance of this partnership lies in the fact that the private sector is more dynamic in terms of development and exploration, especially as it seeks to increase its productivity, which 
positively reflects on the quantity and quality of the services and on reducing the cost of the services.

Three participants agreed that the public sector is responsible for environmental risks, regulation and other legal matters and that both sectors are responsible for risks related to force majeure, labour relations, profits and loss. Another two participants believed that this type of partnership is characterized by the fact that the public sector does not purchase assets for healthcare services but purchases the produced good healthcare services (i.e., the public sector is more interested in output rather than input).

\section{Discussion}

The view of the participants focused on encouraging partnerships between the public sector and the private sector, and they believed that the development witnessed by the kingdom must involve the participation of the two sectors.

Public-private partnership aims to change government activity from the operation of infrastructure and public services to focusing on policy development for the infrastructure sector and monitoring service providers to improve quality, finance the private sector and involve it in taking risks (Nikolic \& Maikisch, 2006). The results of the study revealed that a partnership between the two sectors will help to increase the number of detected cases and limit the cases of delayed diagnosis by involving all healthcare service providers in referral and diagnosis in due time; such a partnership ensures appropriate notification of all cases that are diagnosed and offers the appropriate treatment within guidelines. This finding is in agreement with several studies that have found similar results (Lim, 2005; Pollock \& Price, 2006) and confirmed that the consortium usually undertakes responsibilities for financing, designing, and constructing (or refurbishing) a facility, and or thereafter provides services. The government (or service user) provides the consortium with a revenue stream that is used to repay debts, fund operations and provide a return to investors (Pollock \& Price, 2006).

The results revealed that the participants believed that PPP will achieve a sustainable economy based on knowledge, competitiveness, expertise and diversity, thus achieving economic and social development and better results and output than can be achieved by an individual sector. This aim can be achieved through negotiation, exchanged experiences, expansion of available financial resources and application of high standards. This finding is in agreement with several studies that have found similar results (Nikolic \& Maikisch, 2006; Ricks et al., 2013; Ngoma et al., 2014). First, similar to the results of the Mistarihi and Khasawneh (2015) study, because PPP arrangements usually involve large investments and have been recently introduced by governments as an option to produce and deliver goods and services to the public and because there is little knowledge and experience in establishing and managing these types of hybridized projects, PPP policy makers, partners, managers and researchers have genuine concerns about the outcomes of these partnership arrangements. Second, it is anticipated that PPPs will increase in their usage by governments internationally as an important alternative to the traditional procurement approaches. The development of PPPs in this direction will create further challenges to governments in the sense that PPPs will refrain from being 'mere partnership' arrangements in the trading of 'old' privatization schemes. In response to these two challenges, international PPP experiences should be continually documented, learned and utilized in establishing more potentially successful PPPs. Further, more cooperative 'partnership' efforts between PPP practitioners, scholars and public policy makers should map out the present and future roles of PPPs.

\section{Study Limitations}

This study used a small sample, but the sample was purposeful and sufficient for the research objectives. Moreover, due to the lack of PPPs in the KSA and the difficulty of conducting interviews with the managers concerned, the sample was chosen based on their knowledge and familiarity with the implementation of PPP schemes.

\section{Conclusions}

The study concludes that PPPs provide high-quality services and raise the level of healthcare across the region; furthermore, they reduce the costs of healthcare services compared to the costs in private hospitals. The study showed that PPPs in the human, financial, administrative, organizational, technical, knowledge and research and development fields are based on effective participation in commitment to goals, joint responsibility, development vision and legal accountability to achieve the goals of sustainable development efficiently and effectively. The study also showed that risk sharing is of great importance for the healthcare sector; it helps healthcare facilities to avoid closure and failure and distributes financial flows in an ideal way, as well as reduces the pressure on hospitals to work in a safe investment environment.

Based on the results, the study recommends developing more effective procedures to identify and advertise partnerships, including how the partnership will reduce the cost by sharing it. This development should consider 
not increasing the burden on private hospitals. Risk sharing should be achieved through cooperation and understanding between the two sectors and should be included in decision making regarding the adoption of an appropriate and long-term strategy for partnership between the two sectors. The public sector should direct its interest towards skilful human resources that can use the new equipment and systems efficiently and be interested in a multidisciplinary approach, especially for rare specializations.

\section{Compliance with Ethical Standards}

\section{Informed Consent}

Consent was secured from all the respondents who participated in the study.

\section{Ethical Approval}

All procedures performed in studies involving human participants were in accordance with the ethical standards of the institutional and/or national research committee and with the 1964 Helsinki Declaration and its later amendments or comparable ethical standards. This research study was reviewed and given a favourable opinion by the King Abdulaziz University Research Ethics Committee. In addition to King Abdulaziz University ethical approval, the study has also received ethical approval from the MOH of Saudi Arabia.

\section{Acknowledgements}

We are grateful to all the respondents who participated in this study. Thanks are also due to the anonymous referees for their comments and suggestions that helped produce the paper in its current format.

\section{Competing Interests Statement}

The authors declare that there are no competing or potential conflicts of interest.

\section{References}

Acharya, B., Maru, D., Schwarz, R., Citrin, D., Tenpa, J., Hirachan, S., .. Kohrt, B. (2017). Partnerships in mental healthcare service delivery in low-resource settings: developing an innovative network in rural Nepal. Globalization and health, 13(1), 2. https://doi.org/10.1186/s12992-016-0226-0

Al-Hanawi, M. K., Alsharqi, O., Almazrou, S., \& Vaidya, K. (2018). Healthcare Finance in the Kingdom of Saudi Arabia: a qualitative study of householders' attitudes. Applied health economics and health policy, 16(1), 55-64. https://doi.org/10.1007/s40258-017-0353-7

Alkhamis, A., Hassan, A., \& Cosgrove, P. (2014). Financing healthcare in Gulf Cooperation Council countries: a focus on Saudi Arabia. The International journal of health planning and management, 29(1), e64-e82. https://doi.org/10.1002/hpm.2213

Almalki, M., FitzGerald, G., \& Clark, M. (2011). Health care system in Saudi Arabia: an overview. Eastern Mediterranean health journal, 17(10), 784-93. https://doi.org/10.26719/2011.17.10.784

Alsharqi, O., \& Al-Hanawi, M. K. (2017). A Review of the Implementation of Private Finance Initiatives in UK Hospitals. American Academic \& Scholarly Research Journal, 9(6), 27-31.

Chakravarty, N., Sadhu, G., Bhattacharjee, S., \& Nallala, S. (2015). Mapping private-public-partnership in health organizations: India experience. International Journal of Medicine and Public Health, 5(2), 128-132. https://doi.org/10.4103/2230-8598.153811

Cooper, D. R., \& Schindler, P. S. (2003). Business Research Methods (8th ed.). New York: McGraw-Hill Irwin.

Creswell, J. W., \& Creswell, J. D. (2017). Research design: Qualitative, quantitative, and mixed methods approaches. Sage publications.

Gale, N. K., Heath, G., Cameron, E., Rashid, S., \& Redwood, S. (2013). Using the framework method for the analysis of qualitative data in multi-disciplinary health research. BMC Medical Research Methodology, 13(1), 117-124. https://doi.org/10.1186/1471-2288-13-117

Jamali, D. (2004). Success and failure mechanisms of public private partnerships (PPPs) in developing countries: Insights from the Lebanese context. International Journal of Public Sector Management, 17(5), 414-430. https://doi.org/10.1108/09513550410546598

Ke, Y., Wang, S., Chan, A. P., \& Lam, P. T. (2010). Preferred risk allocation in China's public-private partnership (PPP) projects. International Journal of Project Management, 28(5), 482-492. https://doi.org/10.1016/j.ijproman.2009.08.007

Kinlaw, H. (2008). Public-private investment partnerships in health systems strengthening. Report on Wilton Park 
Conference, $909, \quad 2008 . \quad$ Retrieved 3 Jan, 2018, from: www.wiltonpark.org.uk/documents/conferences/WP909/pdfs/WP909.pdf

Lim, M. K. (2005). Transforming Singapore health care: public-private partnership. Annals-Academy of Medicine Singapore, 34(7), 461-467.

Linder, S. H., \& Vaillancourt Rosenau, P. (2000). Mapping the terrain of public-private policy partnership. In Vaillancourt Rosenau, P. (ed.), Public-private policy partnerships (1-18). Cambridge, MA: MIT Press.

Mathers, N., Fox, N., \& Hunn, A. (2007). Surveys and Questionnaires. Yorkshire: The NIHR RDS for the East Midlands / Yorkshire and the Humber.

Mistarihi, A., \& Khasawneh, S. (2015). Public-private Partnerships (PPPs): Either three-Ps or back to one-P!. Doha Institute for Graduate Studies, Doha: State of Qatar.

MOH. (2010). Strategic Plan 1431-1440 (2010-2020). Riyadh: Ministry of Health.

MOH. (2015). Health statistical year book. Retrieved 25 May, 2017, from http://www.moh.gov.sa/en/Ministry/Statistics/book/Pages/default.aspx

Molchanova, M. (2016) Public-Private Partnership in the System of Regional Healthcare Financing. Economic and Social Changes: Facts, Trends, Forecast, 2(44), 114-132.

Nikolic, I. A., \& Maikisch, H. (2006) Public-private partnerships and collaboration in the health sector: an overview with case studies from recent European experience. Washington (DC): World Bank.

Ngoma, S., Mundia, M., \& Kaliba, C. (2014). Benefits, Constraints and Risks in Infrastructure Development via Public-Private Partnerships in Zambia. Journal of Construction in Developing Countries, 19(1), 15-33.

OECD. (2012). Public-Private Partnerships in the Middle East and North Africa: A Handbook for Policy Makers. Retrieved $21 \quad$ December, 2016, from https://www.oecd.org/mena/competitiveness/PPP\%20Handbook_EN_with_covers.pdf

Pollock, A., \& Price, D. (2006) Privatising primary care. British Journal of General Practice, 56, 565-567.

Raman, A. V., Björkman, J. W. (2009). Public/Private Partnership in Health Care Services in India. Retrieved 26 Nov, 2017, from http://www.pppinharyana.gov.in/ppp/sector/health/report-healthcare.pdf

Reich, M. R. (2002). Public-private partnerships for public health. Harvard Series on Population and International Health, Massachusetts: Harvard University Press.

Ricks, E., van Rooyen, D., Gantsho, M. P., \& ten Ham, W. (2013). Experiences of managers and healthcare personnel involved in a functional healthcare public private partnership. Journal of Psychology in Africa, 23(2), 297-301.

Tahir, M. S. (2017). Public Private Partnerships (PPPs); Innovations and Improvements for Future. Health Care Systems in Pakistan. Professional Medical Journal, 24(1). 1-9. https://doi.org/10.17957/TPMJ/17.3833

The Higher Education Funding Council for England (1998). Practical guide to PFI for higher education institutions, Bristol, U.K.

Van Ham, H., \& Koppenjan, J. (2001). Building public-private partnerships: Assessing and managing risks in port development. Public Management Review, 3(4), 593-616. https://doi.org/10.1080/14616670110070622

Widdus, R. (2001). Public-private partnerships for health: their main targets, their diversity, and their future directions. Bulletin of the World Health Organization, 79(8), 713-720.

Wong, E. L., Yeoh, E. K., Chau, P. Y., Yam, C. H., Cheung, A. W., \& Fung, H. (2015). How shall we examine and learn about public-private partnerships (PPPs) in the health sector? Realist evaluation of PPPs in Hong Kong. Social Science \& Medicine, 147, 261-269. 


\section{Appendix A}

\section{Semi-structured interviews}

Full Name of the interviewee:

Position:

Contact Number:

Email Address:

\section{General Knowledge of Public-Private Partnership}

- How would you describe public-private partnerships?

\section{Benefits of public-private partnerships}

- In your opinion, what are the advantages of implementing a strong public-private partnership in the Kingdom of Saudi Arabia?

- Do you observe any progress in the implementation of public-private partnerships in the Kingdom of Saudi Arabia? How?

- What are the concrete benefits that you have observed or received from the established partnership?

- Would you please elaborate on the key achievements of the partnership/s so far?

- Do you perceive risk sharing, cost sharing and resource sharing as beneficial?

- Which among the three is the most beneficial, in your opinion?

- Between the two partners, which benefits more among the three (sharing risks, sharing costs and sharing resources)?

\section{Challenges in the Implementation}

- What are your perceived challenges, hindrances or barriers in the implementation of the partnership/s?

- Can you elaborate on the legal background for the establishment and maintenance of the partnership/s?

- In your opinion, how can these challenges be addressed?

- Can you think of actions that can prevent the occurrence of these challenges in the future?

\section{Role of the private sector}

- What do you think are the roles of the government in the successful implementation of the partnership in healthcare service delivery?

- What about the roles of the private sector?

- In your opinion, what is/are the particular role/s of the private sector in primary health care, pharmaceuticals and medical supplies, diagnostic services, and human resource development?

- What are the other areas that you think the private sector must give more of its attention to or be more responsible for?

\section{Concluding Questions}

- Do you know any other successful public-private partnerships in this country?

- Is there any other information that you would such as to share about public-private partnerships?

\section{Copyrights}

Copyright for this article is retained by the author(s), with first publication rights granted to the journal.

This is an open-access article distributed under the terms and conditions of the Creative Commons Attribution license (http://creativecommons.org/licenses/by/4.0/). 